\title{
Bax mutation and overexpression inversely correlate with immature phenotype and prognosis of childhood germ cell tumors
}

\author{
RAFFAELE ADDEO ${ }^{1,2}$, STEFANIA CRISCI ${ }^{1}$, VELIA D'ANGELO ${ }^{1}$, BRUNO VINCENZI ${ }^{3}$, \\ FIORINA CASALE ${ }^{1}$, GUIDO PETTINATO ${ }^{4}$, VITTORIA DONOFRIO ${ }^{5}$, RENATA BOLDRINI ${ }^{6}$, \\ RITA ALAGGIO $^{7}$, PAOLA COLLINI ${ }^{8}$, ROBERTA BERTORELLE $^{9}$, MARIA TERESA DI TULLIO $^{1}$, \\ MICHELE CARAGLIA $^{10}$, MONICA TERENZIANI ${ }^{11}$, MARGHERITA LO CURTO ${ }^{12}$ and PAOLO INDOLFI ${ }^{1}$ \\ ${ }^{1}$ Pediatric Oncology Service, Pediatric Department, II University of Naples, Naples; ${ }^{2}$ Oncology Unit, \\ 'San Giovanni Di Dio' Hospital, Frattamaggiore (NA); ${ }^{3}$ Oncology Unit, Campus Bio-Medico University, \\ Rome; ${ }^{4}$ Pathology Department, 'Federico II' University of Naples; ${ }^{5}$ Pathology Division, AORN Santobono, \\ Pausilipon, Naples; ${ }^{6}$ Pathology Service, Hospital Bambin Gesù, Rome; ${ }^{7}$ Pathology Department, University \\ of Padua, Padua; ${ }^{8}$ Pathology Division, National Institute of Tumours, Milan; ${ }^{9}$ Istituto di Oncologia, \\ University of Padua, Padua; ${ }^{10}$ Experimental Pharmacology Unit, National Institute of Tumours \\ 'G. Pascale' of Naples, Naples; ${ }^{11}$ Pediatric Oncology Unit, Istituto Nazionale Tumori, Milan; \\ ${ }^{12}$ Pediatric Department, University of Palermo, Palermo, Italy
}

Received March 31, 2006; Accepted July 26, 2006

\begin{abstract}
Primary childhood germ cell tumors (GCTs) represent a rare and heterogeneous group of tumors that varies in histologic differentiation, age of presentation and clinical outcome. In malignant neoplasms, apoptosis is a prognostic marker and a predictive factor of response to therapy. Therefore, the study of the expression and mutation of molecules involved in the regulation of apoptosis could be useful in order to both predict the clinical outcome and design self-tailored therapeutic approaches. We retrospectively analysed tissue samples of 54 childhood GCTs. The expression of p53 and BAX protein was assessed by immunohistochemistry (IHC). Moreover, we investigated the presence of mutations in the BAX and p53 genes SSCP-PCR and direct sequencing. IHC analysis of BAX protein expression showed that 14 out of 54 tumors $(26 \%)$ had no BAX protein expression, in the remaining 40 patients $(74 \%)$ the intensity
\end{abstract}

Correspondence to: Dr P. Indolfi, Pediatric Oncology Service, Pediatric Department, II University of Naples, Via S. Andrea Delle Dame 4, 80138 Napoli, Italy

E-mail: paolo.indolfi@unina2.it

Dr M. Caraglia, National Cancer Institute Fondazione 'G. Pascale', Experimental Oncology Dept., Experimental Pharmacology Unit, Via M. Semmola, 80131 Naples, Italy

E-mail: michele.caraglia@fondazionepascale.it

Key words: germ cell tumors, childhood, BAX, p53, prognosis, apoptosis of BAX was low in 20 patients $(37 \%)$ and high/ intermediate in $20(37 \%)$. BAX was mutated in 6 patients. p53 was expressed in 43 patients $(79.6 \%)$, was not detectable in the remaining $11(20.4 \%)$ and mutated in only 3 patients. p53 mutational status and expression were not correlated to the overall survival (OS). On the other hand, both IHC score and mutations for BAX were correlated to sacrococcygeal primary localization. BAX mutations were inversely correlated with OS ( $\mathrm{p}=0.0419)$ while BAX IHC intensity was directly correlated with OS $(p=0.0376)$. The stratification for histotype showed a direct correlation between BAX IHC and OS in both immature teratoma $(\mathrm{p}=0.045)$ and mixed malignant $\operatorname{GCT}(\mathrm{p}=0.010)$ while the correlation was lost in mature teratoma $(p=0.300)$. These results indicate that both mutations and BAX protein levels are useful molecular biological markers for prognosis and clinical management of pediatric GCT.

\section{Introduction}

Germ cell tumors (GCTs) are a rare group of tumors in childhood. These tumors share a common presumed cell of origin, the primordial germ cell; they occur in both gonadal and extragonadal sites with different histological presentations from mature and differentiated (i.e. in mature teratoma) to highly anaplastic and aggressive (i.e. in seminoma, Yolk Sac tumors, choriocarcinoma and embryonal carcinoma). The pediatric GCTs are heterogeneous for age, sex, initial localization and clinical behaviour (1). They are substantially different for both pathologic and clinical features from adult GCTs that probably arise from a different stage of germ cell development (1). The small number of cases of childhood 
GCTs has limited the publication of studies on their genetic and molecular abnormalities. Deletions of $1 \mathrm{p} /$ gain of $1 \mathrm{q}$ and +3 were the most common chromosomal abnormalities among the malignant tumors from both sexes (2). Moreover, mature and immature teratomas of all ages displayed normal comparative genomic hybridization profiles with the appropriate chromosome complement (1). Therefore, few data are available on the molecular mechanisms and genes involved in the genesis of these neoplasms and that can be predictive markers of response to chemotherapy.

Apoptotic cell death plays a central role in the pathogenesis and disease progression of cancer as well as in the response to treatment. In malignant neoplasm, the balance of apoptosis and proliferation is shifted towards proliferation, either by increased mitosis and/or reduced apoptosis (3). Several oncogenes and tumor suppressor genes regulate apoptosis. The Bcl-2 family proteins serve as critical regulators in this pathway, acting to either inhibit or promote cell death (4). The pro-apoptotic member of this family, BAX, acts as a tumor suppressor and its inactivation determines tumor growth and reduced apoptosis rate (5). BAX deficient mice indicate that cell death in the normal development of several tissues, such as lymphocytes and ovarian granulosa cells, depends on BAX. These mice show an accumulation of atypical premeiotic germ cells, suggesting a central role for this gene in the control of the meiotic cycle (6). Moreover, downregulation of BAX in germ cells favours germ cell survival (7). In colorectal cancer (8), gastric carcinoma (9) and in acute lymphoblastic leukemia, frameshift mutations of bax are frequently found in tumors with the microsatellite mutator phenotype. Mutations in BAX have been described in a number of human hematopoietic tumor cell lines as well as in gastro-intestinal cancer. Reduced BAX expression was shown to be associated with poor clinical outcome in diffuse aggressive non-Hodgkin lymphoma (10), ovarian cancer (11), metastatic breast carcinoma (12) and pancreatic cancer (8). Immunohistochemical studies have demonstrated that BAX expression was relatively diffuse in some mature teratomas but not in immature teratomas (13) confirming its role in determining lower biological and clinical aggressiveness.

p53 can act as a transcriptional regulator of the gene encoding for BAX, and part of tumor suppressor properties of the $\mathrm{p} 53$ gene can be mediated by transcriptional activation of BAX (14). The p53 gene has been shown to be a key regulator in a wide range of cellular processes, including cell cycle control, DNA repair and programmed cell death (15). Mutation of the p53 tumor suppressor gene is a common feature of human cancers, with $\sim 50 \%$ of tumors estimated to contain mutated $\mathrm{p} 53$ protein. These mutations are clustered in regions of p53 that are essential for binding to DNA in a sequence-specific fashion $(16,17)$. Many studies have reported the presence of wild-type p53 in testicular germ cell tumors of adolescents and adults: high level of p53 does not correlate directly to treatment sensitivity of these tumors, and inactivation of p53 is not a common event in the development of chemotherapy resistance. The role of this gene remains unclear in the pediatric GCT and in non-seminomatous GCT. Patients with embryonal carcinoma showed a specific tumor biology profile with low apoptosis and low p53 and their survival is better than that of the overall patient group.
Hiroshima et al (13) in their study on 24 teratomas have reported that most mature and immature teratomas have a positive immunoreactivity for p53 but mutation of this gene was observed only in one immature teratoma. However, Houldsworth et al (18) identified a small subset of male teratomas with p53 mutations that may account for their resistance to chemotherapy.

To clarify the role of these genes in childhood GCT, we investigated 54 pediatric GCT specimens for mutations in the complete coding sequence of the BAX gene. In addition, we screened for mutations in the DNA binding domain of the p53 gene, since p53 has been implicated in the transcriptional activation of the BAX gene. The primary objective was the definition of the molecular features of GCT and their correlation with the clinical outcome of the patients.

\section{Patients and methods}

Patients and tumor pathology. Paraffin-embedded tissue blocks from 54 samples non-consecutive de novo GCTs, observed in 4 AIEOP centers from April 1991 to December 2002, were collected and processed for mutational analysis of the p53 and BAX genes. Of the 54 studied cases, 33 were female $(61.2 \%)$ and $21(38.8 \%)$ were male. The patients ranged in age from newborn to 16 years, with a median of 613 days. The diagnosis was established by immunohistochemistry (1-3). The tumors included the following histologic types: MT (mature teratoma) 18 cases $(33.3 \%)$, IT (immature teratoma) 21 cases $(38.8 \%)$, EST (endodermal sinus tumor or Yolk Sac tumor) 8 cases $(14.8 \%)$, MXD (mixed germ cell tumor: IT + EST) 6 cases $(11.2 \%)$ and 1 seminoma (1.8\%). Twenty patients $(37 \%)$ had sacrococcygeal disease localization at diagnosis. The tumor samples were obtained at initial diagnosis, before chemotherapy. Patient characteristics are shown in Table I.

Immunohistochemistry. For light microscopy, the sections from each GCT specimen were cut at 3-5 micron, mounted on glass and dried $\mathrm{O} / \mathrm{N}$ at $37^{\circ} \mathrm{C}$. The sections were then deparaffinized in xylene, rehydrated through a graded alcohol series and washed in PBS. This buffer was used for all subsequent washes and for dilution of the antibodies. Tissue sections were heated twice in a microwave oven for 5 min each at $700 \mathrm{~W}$ in citrate buffer ( $\mathrm{pH} \mathrm{6.0)}$ and then processed with the standard streptavidin-biotin-immunoperoxidase method (Dako Universal kit, Dako Corporation, Carpinteria, CA, USA). Rabbit polyclonal immune serum raised against BAX (N-20) (Santa Cruz Biotechnology, Inc., Santa Cruz, CA, USA) at a 1:100 dilution, mouse monoclonal anti-human antibody raised against p53 (Dako, Carpinteria, Cat No. M7001) at a 1:30 dilution, were incubated for $1 \mathrm{~h}$ at room temperature as primary antibodies.

Diaminobenzidine was used as the final chromogen, and hematoxylin as the nuclear counterstain. Negative controls for each tissue section were performed leaving out the primary antibody. The specificity of staining was also confirmed by competition of the primary antibodies with the respective peptide to which they were generated (data not shown). All samples were processed under the same conditions. All slides were independently reviewed by at least two pathologists, they evaluated the staining pattern of the two proteins separately and scored the protein expression in each specimen for the 
percentage of positive neoplastic cells: score 0 , undetectable staining; score 1, from 1 to $30 \%$ of positive cells; score 2 , from 30 to $60 \%$ of positive cells; score $3,>60 \%$ of positive cells. In addition, the intensity of the staining was evaluated for p53 and BAX (respectively indicated as p53i, and BAXi) and scored from 1 to 3 (from low, through medium to high) as compared with the $3+\mathrm{bcl}-2$ intensity of staining of the background to give a semi-quantitative evaluation of the immunostaining. Analysis of the data using such arbitrary cut-offs was highly significant and, therefore, functionally operative.

Isolation of genomic DNA from paraffin-embedded tissue. Paraffin sections of $3 \mu \mathrm{m}$ were deparaffinized with xylene and centrifuged at full speed for $5 \mathrm{~min}$. The pellet was washed twice in ethanol $96 \%$ and centrifuged at full speed for $10 \mathrm{~min}$ at room temperature. After the ethanol was evaporated the samples were processed for DNA extraction. Genomic DNA was extracted with phenol/chloroform as previously described (4).

Mutational analysis for p53. For detection of p53 mutations in the DNA binding region, single stranded conformational polymorphism (SSCP) polymerase chain reaction (PCR) analysis was performed. Genomic DNA was subjected to PCR using oligonucleotide primers for amplification of exons 5-8 of the p53 gene; primer sequences are those of Sturm et al (19). Reaction mixture containing 100-200 ng of DNA, $100 \mu \mathrm{M}$ dNTP, 1.5 unit Taq DNA polymerase stoffel fragment (Applied Biosystems), $1 \mu \mathrm{mol} / \mathrm{l}$ of each primers, $1 \mathrm{mmol} / 1 \mathrm{MgCl}_{2}, 50 \mathrm{mmol} / \mathrm{l}$ TRIS-HCl $\mathrm{pH} 8.8$ total volume of $50 \mu 1$.

Mutational analysis for BAX. The BAX gene consists of 6 exons. Searching for mutations, we performed SSCP-PCR with some changes of the previously described protocol. Exon 1, 2/3, 4, 5 and 6 of the BAX gene were amplified in a $50 \mu 1$ PCR amplification mixture containing 100-200 ng of DNA, $200 \mu \mathrm{M}$ dNTP, 1 unit Taq DNA polymerase, and $2.5 \mathrm{pmol}$ of each primers in $10 \mathrm{mM}$ Tris $\mathrm{pH} 8.3,50 \mathrm{mM} \mathrm{KCl}$, and $1.5 \mathrm{mM} \mathrm{MgCl}_{2}$. Primer sequences, and annealing temperatures are those of Sturm et al and Chou et al $(20,21)$.

SSCP analysis. For SSCP analysis, $5 \mu 1$ of the amplified fragments were diluted in $25 \mu 1$ of loading buffer (0.1\% SDS, $10 \mathrm{mM}$ EDTA, $95 \%$ formamide, $0.05 \%$ xylene xyanole, $0.05 \%$ bromophenol blue). The samples were denatured at $95^{\circ} \mathrm{C}$ for $8 \mathrm{~min}$ and cooled on ice. The denatured fragments were analysed on a $10 \%$ non-denaturing polyacrylamide gel (MDE gel solution, Cambrex Bio Science, Rockland, MA, USA) at $300 \mathrm{~V}$ for $3 \mathrm{~h}$ at $4^{\circ} \mathrm{C}$ in a Bio-Rad electrophoresis chamber (Bio-Rad Laboratories Ltd., Hertfordshire, UK). Single strands were visualized by silver staining.

DNA sequence analysis. In case of band shifts in the SSCP analysis, the samples were purified using GFX ${ }^{\mathrm{TM}}$ PCR DNA purification kit (Amersham Pharmacia Biotech Inc.) and sequenced with a modification of the Sanger method (22) using a fluorescent dye (Big Dye ${ }^{\mathrm{TM}}$ terminator cycle sequencing kit, Applied Biosystems) in a 310 automated DNA sequencer (Applied Biosystems).
Table I. Clinical and molecular patient characteristics.

\begin{tabular}{lc}
\hline Number of patients & 54 \\
Gender & \\
Male vs. female & 21 vs. 33 (38.8\% vs. 61.2\%) \\
Immunohistotype & \\
Mature teratoma & $18(33.3 \%)$ \\
Immature teratoma & $21(38.8 \%)$ \\
Mixed malignant & $15(27.9 \%)$ \\
Site & \\
Sacrococcygeal & $20(37 \%)$ \\
Other & $34(63 \%)$ \\
p53 & \\
p53 wild-type & $51(94 \%)$ \\
p53 mutated & $3(6 \%)$ \\
BAX & \\
BAX wild-type & $48(88 \%)$ \\
BAX mutated & $6(12 \%)$ \\
p53 intensity & \\
Low & \\
High/intermediate & \\
Not established & $15(29(53.7 \%)$ \\
p53 positive cells & $9(16.7 \%)$ \\
Positive & \\
Negative & \\
BAX intensity & \\
Low & \\
High/intermediate & \\
Not established & \\
\hline
\end{tabular}

Statistical analysis. Spearman correlation test or Chi-square test were used to assess relationships between clinical parameters and immuhistochemical or mutational data. Univariate survival analysis for each prognostic variable on overall survival was estimated according to the Kaplan-Meier method (23). The terminal event was death attributable to cancer or non-cancer causes. The statistical significance of the differences in survival distribution among the prognostic groups was evaluated by the log-rank test (24). p-value $<0.05$ was regarded as statistically significant in two-tailed tests. SPSS software (version 10.00, SPSS, Chicago) was used for statistical analysis.

\section{Results}

Analysis of BAX and p53 expression and mutations. Immunohistochemistry analysis of BAX protein expression showed that 14 out of 54 tumors $(26 \%)$ had no BAX protein expression, the remaining 40 samples $(74 \%)$ showed a positive BAX 
Table II. Investigation of the BAX gene in pediatric GCT by DNA-SSCP and DNA sequence analysis.

\begin{tabular}{rccccccc}
\hline Pt. & Exon & Codon & Nucleotide sequence & Amino acid & Nucleotide substitution & Mutation type & Amino acid \\
\hline 1 & 3 & 68 & GAC & Asp & $\underline{\text { CAC }}$ & Transversion & His \\
2 & 2 & 23 & GGG & Gly & GG $\underline{A}$ & Transition & Gly \\
5 & 3 & 41 & GAG & Glu & $\ldots$ AG & Frameshift & $\ldots . .$. \\
13 & 3 & 36 & GGG & Gly & G $\underline{\text { G }}$ & Transversion & Ala \\
41 & 3 & 41 & GAG & Glu & $\ldots$ AG & Frameshift & $\ldots . .$. \\
54 & 3 & 37 & CGA & Arg & GGA & Transversion & Gly \\
\hline
\end{tabular}

staining. The intensity of BAX was low in 20 patients (37\%) and high/intermediate in the remaining 20 (37\%) (Table I). The study of genomic DNA of BAX showed the absence of mutations in exons $1,4,5$ and 6 while mutations of exons 2 and 3 were present in 6 patients (Table II). Five patients had an immature teratoma and the remaining one patient a Yolk Sac tumor. The patients with immature teratoma were 4 females ( 2 with sacrococcygeal, 1 ovarian and 1 abdominal disease localization) and 1 male (with sacrococcygeal disease localization). The patient with Yolk Sac tumor was a male with disease localization at testis. The mutations were three transversions at exon 3 with a single amino acid substitution in two females (ovarian and abdominal localization, respectively) and one male (sacrococcygeal localization) with immature teratoma (Table II). Moreover, two frameshifts of exon 3 were observed in 2 females with immature teratoma at sacrococcygeal localization and a transition not resulting in amino acid changes was found in the remaining patient with Yolk Sac tumor of testis (Table II).

p53 was expressed in 43 patients (79.6\%) and was not detectable in the remaining 11 patients $(20.4 \%)$ (Table I). In addition, the intensity of the staining was evaluated as described in Materials and methods and showed high/intermediate p53 levels in 16 patients $(29.6 \%)$, low intensity in 29 patients $(53.7 \%)$ while the remaining $9(16.7 \%)$ had no detectable levels of $\mathrm{p} 53$ (Table I). We first evaluated the mutational status of p53 in all the patients enrolled in the study with SSCP-PCR and subsequently by DNA sequencing. We found mutations of $\mathrm{p} 53$ in 3 patients (6\%, two males and one female) while in the remaining 51 patients $(94 \%)$ p53 gene was wild-type (Table II). The mutations were all point mutations and were all placed in the sequence-specific DNA binding region of the protein and consequently they were able to affect the binding of p53 to DNA and its anti-oncogene function. In the three cases, abnormal band shift was an indicator for point mutations. Two mature teratomas showed the same intronic mutation of exon 7 with the substitution of a guanine with a cytosine while the remaining immature teratoma had a wide frameshift resulting in truncation. In all 3 patients a high expression of $\mathrm{p} 53$ was also detected by immunohistochemistry (Table I).

Statistical analysis of molecular markers in the prognosis of pediatric GCT patients. We first correlated in univariate analysis the molecular markers with clinical parameters. No statistically significant correlation was identified between BAX and p53 status (as IHC staining or mutational status)
Table III. Correlations between IHC score for BAX and clinical parameters.

\begin{tabular}{lrcc}
\hline & BAX 0 & BAX 1-2-3 & P \\
\hline Age & & & \\
$\geq 18$ months & 8 & 18 & 0.763 \\
$<18$ months & 6 & 22 & \\
Sex & & & \\
Female & 10 & 23 & 0.359 \\
$\quad$ Male & 4 & 17 & \\
Site & & & \\
Sacrococcygeal & 10 & 10 & $\mathbf{0 . 0 3 1}$ \\
$\quad$ Other & 4 & 30 & \\
Immunohistotype & & & \\
Mature teratoma & 5 & 13 & 0.214 \\
Other & 9 & 27 & \\
Immature teratoma & 8 & 13 & 0.269 \\
Other & 6 & 27 & \\
$\quad$ Mixed malignant GCT & 3 & 3 & 0.642 \\
Other & 11 & 37 & \\
p53 intensity & & & \\
$\quad$ Negative & 3 & 6 & 0.970 \\
Positive & 11 & 34 & \\
p53 positive cells & & & \\
$\quad$ Negative & 4 & 7 & 0.705 \\
Positive & 10 & 33 & \\
\hline
\end{tabular}

In bold, significant statistical correlation.

(respectively, Pearson's coefficient: $0.180 ; \mathrm{p}=0.349$ and Pearson's coefficient: $0.211 ; \mathrm{p}=0.166$ ). Moreover, no statistical correlation was identified between IHC staining for p53 and gender (Pearson's coefficient: $-0.04 ; \mathrm{p}=0.948$ ), age (Pearson's coefficient: $0.124 ; \mathrm{p}=0.341$ ), tumor localization (Pearson's coefficient: $0.209 ; \mathrm{p}=0.237$ ) and histotype (Pearson's coefficient: $0.045 ; \mathrm{p}=0.867)$. Moreover, performing the same analysis, we failed to identify statistically significant correlation between the mutational status of p53 and gender (Pearson's coefficient: $-0.174 ; p=0.451$ ), age (Pearson's coefficient: 
Table IV. Correlations between BAX mutation and clinical parameters.

\begin{tabular}{|c|c|c|c|}
\hline & \multicolumn{2}{|c|}{ BAX mutation } & \multirow[b]{2}{*}{$\mathrm{P}$} \\
\hline & $\begin{array}{c}\text { BAX } \\
\text { wild-type }\end{array}$ & $\begin{array}{c}\text { Mutated } \\
\text { BAX }\end{array}$ & \\
\hline \multicolumn{4}{|l|}{ Age } \\
\hline$\geq 18$ months & 24 & 2 & 0.672 \\
\hline$<18$ months & 24 & 4 & \\
\hline \multicolumn{4}{|l|}{ Sex } \\
\hline Female & 29 & 4 & 1.000 \\
\hline Male & 19 & 2 & \\
\hline \multicolumn{4}{|l|}{ Site } \\
\hline Sacrococcygeal & 17 & 3 & 0.046 \\
\hline Other & 31 & 3 & \\
\hline \multicolumn{4}{|l|}{ Immunohistotype } \\
\hline Mature teratoma & 18 & 0 & 0.236 \\
\hline Other & 30 & 6 & \\
\hline Immature teratoma & 19 & 2 & 0.852 \\
\hline Other & 29 & 4 & \\
\hline Mixed malignant GCT & 5 & 1 & 0.830 \\
\hline Other & 43 & 5 & \\
\hline \multicolumn{4}{|l|}{ p53 intensity } \\
\hline Negative & 7 & 2 & 0.545 \\
\hline Positive & 41 & 4 & \\
\hline \multicolumn{4}{|l|}{ p53 positive cells } \\
\hline Negative & 10 & 1 & 0.746 \\
\hline Positive & 38 & 5 & \\
\hline
\end{tabular}

In bold, significant statistical correlation.

-0.218; $\mathrm{p}=0.191$ ), tumor localization (Pearson's coefficient: $0.178 ; \mathrm{p}=0.358$ ) and histotype (Pearson's coefficient: 0.245; $\mathrm{p}=0.121)$. p53 mutational status and expression were not correlated with the OS of the population after stratification for immunohistotype (data not shown). On the other hand, IHC score for BAX was statistically correlated with the primary localization of the disease at sacrococcygeal site $(\mathrm{p}=0.031)$ while it was not correlated with age $(p=0.763)$, sex $(p=0.359)$, immunohistotype: mature teratoma $(p=0.214)$, immature teratoma $(p=0.269)$, mixed malignant GCT $(\mathrm{p}=0.642), \mathrm{p} 53$ IHC intensity $(\mathrm{p}=0.970)$ and $\mathrm{p} 53$ positive IHC staining $(\mathrm{p}=0.705)$ (Table III). Bax mutations were correlated only with the primary localization of the disease at sacrococcygeal site $(p=0.046)$, but not with age $(p=0.672)$, sex $(p=1.000)$, immunohistotype: mature teratoma $(p=0.236)$, immature teratoma $(\mathrm{p}=0.852)$, mixed malignant GCT $(\mathrm{p}=0.830), \mathrm{p} 53$ IHC intensity $(\mathrm{p}=0.545)$ and $\mathrm{p} 53$ positive IHC staining $(\mathrm{p}=0.746)$ (Table IV). BAX mutations and expression were also correlated with OS of the patients enrolled in the study. We found that BAX mutations were inversely correlated with OS $(\mathrm{p}=0.0419)$ while BAX IHC
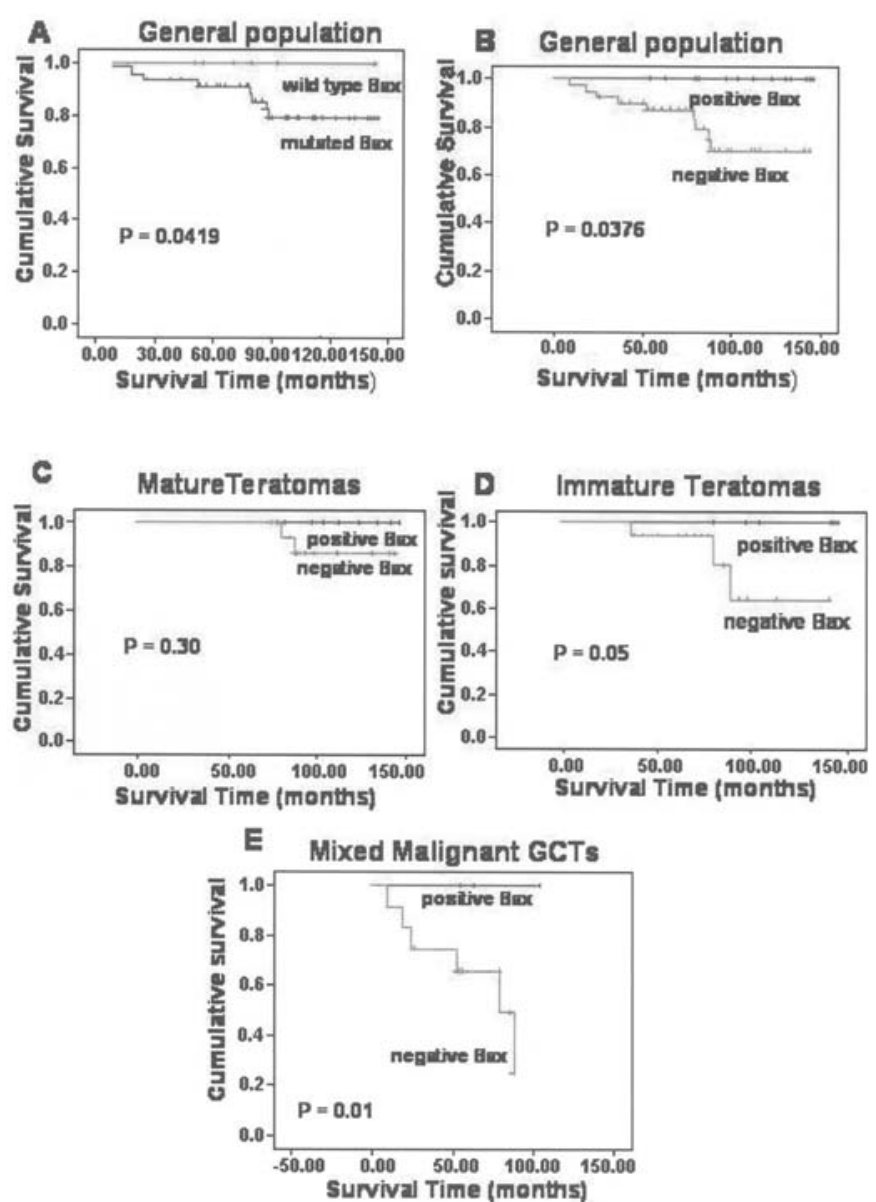

Figure 1. Overall survival (OS) according to mutation and expression of Bax. Univariate survival analysis for (A) mutated vs. wild-type Bax and for expression vs. not expression of Bax in (B) general population, (C) mature teratomas, (D) immature teratomas and (E) mixed malignant GCTs on OS estimated according to the Kaplan-Meier method.

intensity was directly correlated with OS $(\mathrm{p}=0.0376)$ (Fig. 1A and $\mathrm{B}$, respectively, and Table $\mathrm{V}$ ). The population was also stratified for histotype and the univariate statistical analysis was performed. It was found that BAX IHC was directly correlated with OS in both immature teratoma $(\mathrm{p}=0.045)$ and mixed malignant GCT $(\mathrm{p}=0.010)$ while the correlation was lost in mature teratoma ( $\mathrm{p}=0.300)$ (Fig. 1C-E and Table V).

\section{Discussion}

Primary childhood germ cell tumors represent a heterogeneous group of tumors that varies with regard to histological differentiation, age of presentation and outcome. The scarcity of pediatric GCTs is the cause of few genetic and molecular studies reported. Deletion of $1 \mathrm{p} /$ gain of $1 \mathrm{q}$ and +3 were the most common chromosomal abnormalities among the malignant tumors from both sexes (2). Therefore, mature and immature teratomas of all ages displayed normal comparative genomic hybridization profiles with the appriopriate chromosome complement (1). Scarce data are available on the molecular mechanisms and genes involved in the genesis of these neoplasms and that can activate the responsiveness to chemotherapy of pediatric GCTs. 
Table V. Overall survival (OS) and molecular parameters in pediatric GCT patients in univariate analysis.

\begin{tabular}{lccc}
\hline & Median survival 95\% & Confidence interval & P \\
\hline BAX mutation & & & \\
$\quad$ Mutated & 124.67 & $104.00-135.99$ & $\mathbf{0 . 0 4 1 9}$ \\
$\quad$ Wild-type & 139.05 & $118.63-141.53$ & \\
Bax IHC intensity & 120.35 & $106.54-134.16$ & $\mathbf{0 . 0 3 7 6}$ \\
$\quad$ Negative & 141.40 & $123.45-143.50$ & \\
$\quad$ Positive & & & \\
Bax IHC intensity in mature teratoma & 131.78 & $124.19-145.37$ & 0.30 \\
$\quad$ Negative & 136.76 & $128.11-139.31$ & \\
$\quad$ Positive & & & \\
Bax IHC intensity in immature teratoma & 117.18 & $95.54-138.68$ & $\mathbf{0 . 0 4 5}$ \\
$\quad$ Negative & 138.21 & $124.76-149-03$ & \\
$\quad$ Positive & & & \\
Bax IHC intensity in mixed malignant GCT & 112.76 & $96.23-131.90$ & $\mathbf{0 . 0 1}$ \\
$\quad$ Negative & 144.43 & $106.54-134.16$ & \\
$\quad$ Positive & & \\
\hline
\end{tabular}

In bold, significant statistical correlation.

Apoptotic cell death plays a central role in the pathogenesis and disease progression of cancer as well as in the response to treatment. In malignant neoplasm, the balance of apoptosis and proliferation is shifted towards proliferation, either by increased mitosis and/or reduced apoptosis (3). Bax and p53 are involved in the regulation of apoptotic process and could therefore be important in the determination of prognosis of diseases that are finely regulated by the balance of apoptotic and proliferative processes. Data exist on the correlation between Bax expression and prognosis of human cancers (10-12,25). Moreover, a loop between p53 and Bax exists since the former was shown to induce the expression of the pro-apoptotic mitochondrial protein $(26,27)$. On the basis of these considerations, we evaluated the mutational status and the expression of these proteins in a series of 54 childhood GCTs in order to assess the statistical significance of these events in the determination of this heterogeneous disease. p53 mutations in this set of tumors were very infrequent and did not correlate with any clinical and pathological parameters or with OS. On the other hand, Bax mutations were relatively more frequent and all except one affected the correct sequence of the gene likely modifying also the function. Bax mutations were only correlated with the primary localization of the disease at sacrococcygeal site while the correlation with the other clinical and pathological parameters was lost. The presence of mutations in Bax was inversely correlated with the OS of the general population. Similarly, Bax was less expressed in disease at primary localization at sacrococcygeal site. GCTs localized at sacrococcygeal site have also generally a worse prognosis if compared with the other localizations. Bax expression was directly correlated with the OS in the general population and this correlation was conserved after stratification for immunohistotype in immature teratoma and mixed malignant teratoma, but was lost in the mature teratoma subset patients. These data are in agreement with the prognosis and differentiation status of the different GCT immunohistotypes. It is well established that mature teratomas have a good prognostic profile based on its well differentiated status and on the high apoptotic index and p53 expression (13). Previous studies have been performed in order to demonstrate correlation between p53 and Bax expression and the chemosensitivity of GCTs, but they failed to find any statistically significant correlation (15). On the other hand, the hypersensitivity of human testicular tumors to etoposide was associated to functional p53 and high Bax:Bcl-2 ratio (28). Conversely, mutation of p53 are associated with resistance to cisplatin in male GCTs (18). To our knowledge, the present study defines for the first time a series of Bax mutations in childhood GCTs and we also found that the mutations correlate with OS of these patients. However, we suggest that the IHC evaluation of Bax could be feasible and less expensive in order to obtain a significant prognostic parameter in this series of patients. A computer-based prediction of $3 \mathrm{D}$-structure of the proteins encoded by the mutated Bax genes found in these patients will be performed in order to define the involvement of these mutations on the function of Bax.

In conclusion, this is the first study on both mutational and expression status of p53 and Bax in patients affected by pediatric GCTs. These data clearly suggest that IHC detection of Bax must be performed in order to identify a subset of patients with poor prognosis who need more aggressive surgical and medical treatments in order to eradicate their disease. On the other hand, Bax mutations are rare and their 
identification does not allow an improvement of the prognostic definition of the disease.

\section{Acknowledgements}

We would like to thank Professor Salvatore Cozzolino and Dr Olga De Castro (Vegetable Biology Department, 'Federico II' University of Naples, Italy) for their technical support in sequencing of the p53 gene.

\section{References}

1. Schneider DT, Schuster AE, Fritsch MK, Calaminus G, Gobel U, Harms D, et al: Genetic analysis of mediastinal non-seminomatous germ cell tumors in children and adolescents. Genes Chromosomes Cancer 34: 115-125, 2002.

2. Bussey KJ, Lawce HJ, Himoe E, Shu XO, Suijkerbuijk RF, Olson SB, et al: Chromosomes 1 and 12 abnormalities in pediatric germ cell tumors by interphase fluorescence in situ hybridization. Cancer Genet Cytogenet 125: 112-118, 2001.

3. Mullauer L, Gruber P, Sebinger D, Buch J, Wohlfart S and Chott A: Mutations in apoptosis genes: a pathogenetic factor for human disease. Mutat Res 488: 211-231, 2001

4. Reed JC: Bcl-2 family proteins. Oncogene 17: 3225-3236, 1998.

5. Yin C, Knudson CM, Korsmeyer SJ and Van Dyke T: BAX suppresses tumorigenesis and stimulates apoptosis in vivo. Nature 385: 637-640, 1997.

6. Knudson CM, Tung KSK, Tourtellotte WG, Brown GA and Korsmeyer SJ: BAX-deficent mice with lymphoid hyperplasia and male germ cell death. Science 270: 96-99, 1995.

7. Yan W, Suominen J, Samson M, Jegou B and Toppari J: Involvement of Bcl-2 family proteins in germ cell apoptosis during development in the rat and pro-survival effect of stem cell factor on germ cells in vitro. Mol Cell Endocrinol 165: 115-129, 2000.

8. Rampino N, Yamamoto H, Ionov Y, Li Y, Sawai H, Reed JC, et al: Somatic frameshift mutations in the BAX gene in colon cancers of the microsatellite mutator phenotype. Science 275 : 967-969, 1997.

9. Yamamoto H, Itoh F, Fukushima H, Adachi Y, Itoh H, Hinoda Y, et al: Frequent Bax frameshift mutations in gastric cancer with high but not low microsatellite instability. J Exp Clin Cancer Res 18: 103-106, 1999.

10. Gascoyne RD, Krajewska M, Krajewsky S, Connors JM and Reed JC: Prognostic significance of BAX protein in diffuse aggressive non-Hodgkin's lymphoma. Blood 90: 3173-3178, 1997.

11. Tai YT, Lee S, Niloff E, Weiman C, Strobel T and Cannistra SA: Bax protein expression and clinical outcome in epithelial ovarian cancer. J Clin Oncol 16: 2583-2590, 1998.

12. Krajewsky S, Blomquist C, Franssila K, Krajewska M Wasenius VM, Niskanen E, et al: Reduced expression of proapoptotic gene $\mathrm{BAX}$ is associated with poor response rates to combination chemotherapy and shorter survival in women with metastatic breast adenocarcinoma. Cancer Res 55: 4471-4478, 1995.
13. Hiroshima K, Toyozaki T, Iyoda A, Yusa T, Fujisawa T and Ohwada H: Apoptosis and proliferative activity in mature and immature teratomas of mediastinum. Cancer 92: 1798-1806, 2001.

14. Miyashita T and Reed JC: Tumor suppressor p53 is a direct transcriptional activator of the human bax gene. Cell 80: 293-299, 1995.

15. Mayer F, Stoop H, Scheffer GL, Scheper R, Oosterhuis JW, Looijenga LH, et al: Molecular determinants of treatment response in human germ cell tumors. Clin Cancer Res 9: 767-773, 2003.

16. Wang XW and Harris CC: p53 tumor-suppressor gene: Clues to molecular carcinogenesis. J Cell Physiol 173: 247-255, 1997.

17. Sheikh MS and Fornace AJ Jr: Role of p53 family members in apoptosis. J Cell Physiol 182: 171-181, 2000.

18. Houldsworth J, Xiao H, Murty VV, Chen W, Ray B, Reuter VE, et al: Human male germ cell tumor resistance to cisplatin is linked to TP53 gene mutation. Oncogene 16: 2345-1349, 1998.

19. Sturm I, Kohne CH, Wolff G, Petrowsky H, Hillebrand T, Hauptmann S, et al: Analysis of the p53/BAX Pathway in colorectal cancer: low BAX is a negative prognostic factor in patients with the resected liver metastases. J Clin Oncol 5: 1364-1374, 1999.

20. Sturm I, Papadopulos S, Hillebrand T, Benter T, Luck HJ, Wolff $\mathrm{G}$, et al: Impaired Bax protein expression in breast cancer: mutational analysis of the BAX and the p53 gene. Int J Cancer 87: 517-521, 2000.

21. Chou D, Miyashita T, Mohrenweiser HW, Ueki K, Kastury K, Druck T, et al: The BAX gene maps to the glioma candidate region at $19 q 13.3$, but is not altered in human gliomas. Cancer Genet Cytogenet 88: 136-140, 1996.

22. Sanger F, Air GM, Barrell BG, Brown NL, Coulson AR and Fiddes CA: Nucliotide sequence of bacteriophage phi X174 DNA. Nature 265: 687-695, 1977.

23. Kaplan EL and Meier P: Nonparametric estimation from incomplete observations. J Am Stat Assoc 53: 457-481, 1958.

24. Peto R, Pike MC and Armitage P: Design and analysis of randomised clinical trials requiring prolonged observation of each patient. Br J Cancer 35: 1-39, 1977.

25. Friess H, Lu Z, Graber HU, Zimmerman A, Adler G, Korc M, et al: BAX but not bcl-2, influences the prognosis of human pancreatic cancer. Gut 43: 414-421, 1998.

26. Burns FT and El-Deiry WS: The p53 pathway and apoptosis. J Cell Physiol 181: 231-239, 1999.

27. Harnois C, Demers M-J, Bouchard V, Vallée K, Gagné D, Fujita N, et al: Human intestinal epithelial crypt cell survival and death: Complex modulations of Bcl-2 homologs by Fak, PI3-K/Akt-1, MEK/Erk, and p38 signaling pathways. J Cell Physiol 198: 209-222, 2004.

28. Chresta CM, Masters JR and Hickman JA: Hypersensitivity of human testicular tumors to etoposide-induced apoptosis is associated with functional p53 and a high Bax:Bcl-2 ratio. Cancer Res 56: 1834-1841, 1996. 